REVISTA DE DERECHO UNED, NÚM. 21, 2017

\title{
LOS RETOS DEL DERECHO DEL TRABAJO EN EL SIGLO XXI. PROPUESTAS DE CAMBIO EN UNA ÉPOCA DE TRANSICIÓN
}

\author{
XXI CENTURY LABOUR LAW. CHALLENGES AND CHANGE \\ PROPOSALS IN A TRANSITION TIME
}

\author{
Alejandra Selma Penalva \\ Profesora Titular. Derecho del Trabajo y de la Seguridad Social \\ Universidad de Murcia
}

Resumen: La situación laboral de un país, resulta un buen indicador práctico de su condición económica. Pero no solo eso. No se puede olvidar que las condiciones en las que se encuentre el mercado de trabajo condicionarán el nivel de recursos de los que disponga la Seguridad Social, y con ello, el futuro próximo de nuestro sistema de pensiones. De tal forma quizá sea el momento de emprender cierto tipo de reformas con el fin de incentivar la cotización y minimizar el fraude. En el presente trabajo se analizan con detenimiento los distintos problemas de los que actualmente adolece el mercado de trabajo español al tiempo que se plantean ciertas estrategias de reforma que podrían ayudar a mejorar la situación económica de la Seguridad Social. tivas.

Palabras clave: mercado de trabajo, reformas, futuro, perspec-

Abstract: The employment situation of a country is an economic indicator, but not only that. We cannot forget that the current situation of the labour market will determine the level of resources available at Social Security, and with it, the future of our pension system. May be the time to undertake certain type of reforms to encourage the quote and minimize the fraud. This paper analyzes with detail dif- 
ferent problems of which currently suffers Spanish laobur market to improve the economic situation of the Social Security.

Keywords: labour market, reforms, future prospects.

Recepción original: 21/09/2017

Aceptación original: 27/10/2017

Sumario: I. Consideraciones iniciales. La excesiva temporalidad del mercado de trabajo nacional. II. Trabajo negro o economía sumergida. III. Falso trabajo autónomo. IV. Reflexiones en torno a la situación actual y sus posibles soluciones. V. Bibliografía.

\section{CONSIDERACIONES INICIALES. LA EXCESIVA TEMPORALIDAD DEL MERCADO DE TRABAJO NACIONAL}

El mercado de trabajo no es un mercado perfecto. Adolece de múltiples defectos que el legislador intenta atemperar a través de distintas normas jurídicas, muchas veces sin conseguirlo. Pero aunque es el desempleo el problema más acuciante al que éste se debe enfrentar, no es el único. La escasez de empleo se presenta indisolublemente unida a la falta de empleo estable y de calidad, de forma que el problema relativo al elevado desempleo se encuentra en la práctica estrechamente vinculado al generado por la precariedad laboral.

Tan estrecha es esta relación que puede afirmarse que cuanto más elevada sea la oferta de puestos de trabajo y menor la mano de obra disponible, también serán mejores las condiciones laborales ofertadas. Por el contrario, cuando un elevado número de demandantes de empleo se ve obligado a concurrir a una reducidísima oferta de puestos de trabajo (como tristemente ha ocurrido en España con ocasión de la crisis económica), la calidad en el empleo disminuye. A estos efectos, convienen tener en cuenta que la precariedad laboral se origina por múltiples factores; y uno de ellos es la utilización excesiva de la contratación laboral temporal.

Desde el cambio de siglo, las formas de contratación laboral temporal (sea ésta a tiempo completo o parcial) irrumpen en la sociedad con más fuerza, apoyándose en la regulación legal, que cada vez les es más favorable ${ }^{1}$. Se produce así una forma lícita de inestabilidad laboral, puesto que se recurre a modalidades de contratos de trabajo ex-

\footnotetext{
${ }^{1}$ Sirva como ejemplo las repercusiones de la Ley 12/2001 sobre el contrato de trabajo a tiempo parcial y el contrato de trabajo temporal, respectivamente, arts.12 y 15 ET.
} 
presamente contempladas por la ley, pero que conllevan un nivel de protección menor que lo que correspondería a un contrato de trabajo considerado «típico»o «modélico»².

Tan acusada es la contratación temporal en nuestro país, que el contrato indefinido ha pasado a convertirse en una modalidad prácticamente residual, concentrando apenas el 7\% del total de los contratos de trabajo concertados a lo largo del año ${ }^{3}$. Puede incluso afirmarse que la contratación laboral temporal ha pasado a representar la regla general en lugar de la opción excepcional con que el ordenamiento jurídico la configuró, sin que los sucesivos incentivos a la contratación indefinida con que el legislador intenta hacer más atractiva para las empresas la contratación estable ${ }^{4}$, ni tampoco los límites a la utilización encadenada de sucesivos contratos temporales previstos en el art. 15.5 ET, hayan conseguido por el momento invertir esta tendencia.

A la vista de los datos estadísticos, puede incluso afirmarse que pese a las críticas que por el momento recibe cualquier propuesta relativa a la introducción en nuestro sistema jurídico de un contrato laboral único, nuestro modelo de relaciones laborales avanza de forma imparable hacia un contrato de trabajo único esta vez no de «derecho" sino de "hecho", pues más de 9 de cada 10 contratos de trabajo firmados a lo largo del año son contratos temporales, casi todos ellos concertados bien en la modalidad de contrato eventual, bien como contrato para obra o servicio determinado.

Pero no todas las formas de precariedad laboral se apoyan en la utilización abusiva de la contratación temporal, sino que hoy en día

${ }^{2}$ Esta nueva forma lícita de precariedad laboral, no es exclusiva de nuestro ordenamiento jurídico, sino que acontece en múltiples sistemas. Por ejemplo, la doctrina argentina reconoce que esta «tendencia registrada está vinculada con los cambios operados en el Derecho del Trabajo mismo, que habilita la posibilidad de que, en los nuevos contratos de trabajo, y en nombre de la disminución de los costos laborales para las empresas, los trabajadores dependientes sufran la pérdida de garantías que vinculaban antes el salario con diversos institutos de protección (básicamente salud, previsión social, e indemnización por cese del contrato). Estas nuevas normas laborales, integran lo que Alain Supiot denomina «derecho del trabajo de segundo tipo», que alude a los nuevos contratos precarios -es decir, desvinculados de garantías o con esos vínculos garantistas debilitados-, y siguen siendo no obstante contratos de trabajo". SuPIot, A., Trabajo y empleo: transformaciones del trabajo y futuro del Derecho del Trabajo en Europa, Tirant lo Blanch, Valencia, 1999.

${ }^{3}$ Éstos y otros muchos datos anuales se reflejan en AAVV, «Memoria sobre la situación socioeconómica y laboral de España (2016)», Consejo Económico y Social, Madrid, 2016.

${ }^{4}$ Como pone de manifiesto Galiana Moreno, J.M., «Algunos tópicos e incongruencias de las reformas del "mercado de trabajo», Nueva revista española de derecho del trabajo, núm. 161, 2014, págs. 41-58. 
se presentan otras muchas formas de fraude que parten de una utilización ilícita o abusiva de las normas. En este grupo quedarían encuadradas todas las formas de "huída ilícita del Derecho del Trabajo» que nacieron en el siglo pasado, pero han encontrado en el nuevo siglo, amparadas por la diversificación y modernización de las formas productivas actuales, el campo óptimo para proliferar. Se pueden resumir en: trabajo negro, trabajo ilícito y autonomía aparente. Cada una de ellas, por su importancia, merece una explicación detallada.

\section{TRABAJO NEGRO O ECONOMÍA SUMERGIDA}

Con esta expresión coloquial, en realidad se hace referencia a «trabajo no formalizado» o "no declarado». Por este motivo, este adjetivo especificativo puede aplicarse tanto a formas de trabajo por cuenta propia como por cuenta ajena. Aunque el contrato se perfecciona desde el momento en que se produce la coincidencia de voluntades sobre el objeto y la causa de la obligación que se establezca (art. 1261 CC), puede ocurrir que las partes intenten encubrir la relación que han iniciado con el fin de eludir sus obligaciones fiscales y de cotización a la Seguridad Social. Posiblemente el trabajo negro haya existido siempre, lo que ocurre, es que en la etapa productiva tan competitiva que caracteriza al siglo XxI, se hace especialmente tentador este mecanismo para intentar restringir los posibles costes a los que tenga que hacer frente una moderna estructura empresarial.

El trabajo negro no sólo no ha sido formalizado sino que además, y en ello se diferencia de la contratación laboral tácita (8.1 ET), trata de pasar desapercibido para evitar la aplicación de las consecuencias legales que precisamente trata de eludir. Es una forma de fraude sí, pero no sólo a los derechos de los trabajadores dependientes ni al ordenamiento laboral: constituye un fraude a todo el sistema económico en general puesto que genera un trabajo productivo que no se computa. No crea riqueza teórica ni contribuye al sustentar el gasto público. De entre las posibles formas de precariedad esta será quizá la que ocasione consecuencias más duras para el trabajador.

Y es que se obstaculiza de esta manera la aplicación de las normas laborales relativas a la extinción causal del contrato, las indemnizaciones por despido que fija el ET, el mínimo salarial pactado por el convenio colectivo aplicable al sector de actividad de la que forma parte la actividad no declarada, etc. Al mismo tiempo que tampoco puede impedir el ejercicio abusivo de las facultades empresariales de control y sanción ni se puede garantizar un cumplimiento correcto de 
las obligaciones legales impuestas al empresario en materia de prevención de riesgos laborales.

Pero no sólo eso: a los sujetos que prestan el servicio se les excluye también de la protección por el régimen público de Seguridad Social, por lo que (salvo las consecuencias que deriven del reconocimiento de una situación de "alta de pleno derecho») se verán alejados de la protección social prevista en nuestro ordenamiento jurídico ante las posibles contingencias que puedan sobrevenir a lo largo de la vida de un trabajador (desempleo, incapacidad temporal o permanente, maternidad, jubilación, etc.) y de la protección de sus familiares (orfandad y viudedad). Íntimamente unido al problema expuesto, se presenta el relacionado con el percibo de prestaciones indebidas a cargo de la Seguridad Social, situación que sin duda muchas veces inspira y fomenta la economía sumergida, pues posibilitará fingir que se reúnen los presupuestos objetivos de su devengo, cuando en realidad, la realización de una actividad profesional es causa automática de extinción de la citada prestación (desempleo, jubilación, y en general, cualquier prestación prevista para hacer frente a carencia de rentas del solicitante).

A estos efectos, procede recordar que la mera falta de formalización del contrato de trabajo no puede conllevar la expulsión del ordenamiento jurídico laboral de la relación iniciada cuando lo que se está prestando es un trabajo dependiente (1.1 y 15.3 ET). El único inconveniente es que, para solucionar cualquier controversia suscitada entre las partes durante la ejecución del contrato se exige la previa constatación, vía jurisprudencial, de la verdadera naturaleza jurídica del vínculo. A estos efectos conviene subrayar que toda reclamación jurisdiccional de los derechos laborales que una parte considera perjudicados necesita previamente probar la existencia de la relación contractual, y posteriormente, la naturaleza dependiente o independiente del trabajo llevado a cabo. Sólo entonces, una vez constatada la existencia de una auténtica relación laboral podrá el juez exigir el cumplimiento de los derechos y obligaciones que contempla la legislación laboral. Es entonces cuando se aprecia que el trabajo negro se enfrenta a un problema de prueba: en estos casos, será difícil constatar que se realiza o se ha realizado una prestación de servicios para un concreto empleador, y más aún, que ésta se ha llevado a cabo en régimen de dependencia laboral.

En cualquier caso, ante este tipo de situaciones, serán los distintos indicios concurrentes en el caso los que permitirán calificar la relación controvertida. Así, en muchas ocasiones y aunque se trate de un 
contrato de trabajo no declarado, la prestación de servicios se realizará en la sede empresarial o en lugares determinados por el empresario, ajustándose a una jornada de trabajo concreta, y dando lugar a una retribución periódica (aunque normalmente percibida en metálico para evitar rastro). $\mathrm{Al}$ respecto nuestros jueces y tribunales vienen insistiendo en que la permanencia de la relación o al menos su continuación en el tiempo es una característica muy importante en los casos que se pretenda revelar la existencia de una prestación dependiente no declarada, pues facilita la prueba de que el servicio se viene prestando con habitualidad para un mismo receptor.

Pese a todo, existe un factor que no se pude dejar de destacar y que complica el problema de identificación de los fenómenos de trabajo negro en nuestro país: en muchas ocasiones este tipo de contratos no formalizados se conciertan con entes empresariales que realizan una actividad productiva en el mercado de bienes y servicios de la que tampoco han dejado constancia (al menos, a efectos administrativos y fiscales). Y es que obviamente, una empresa «inexistentes» no puede ser titular de derechos y obligaciones, y por lo tanto, no puede actuar como sujeto de una relación laboral, sin revelar con ello su existencia. De esta forma, como se ha adelantado, los supuestos de empleo no declarado pueden incluso presentarse insertos en el seno de un entramado mucho más amplio de situaciones ilícitas.

Para complicar todavía más el panorama descrito, en los últimos años se empieza a constatar que en ocasiones simplemente la falta de regulación jurídica de la actividad en cuestión (o una regulación jurídica incompleta o defectuosa) la que condena al ámbito de la economía sumergida a ciertas formas de colaboración productiva que se pueden denominar «emergentes».

$\mathrm{Y}$ es que al respecto no se puede negar que en los últimos años, potenciadas sin duda por la crisis económica, han proliferado distintos tipos de actividades humanos que se vienen denominando «trabajos colaborativos» que se mantienen al margen del derecho. Son diversos los factores que explican este hecho: por una parte, suelen tratarse de actividades que reportan escasos ingresos (que además suelen ser ocasionales) al sujeto que los presta; y por otra, se presentan en ámbitos en los que su falta de regulación puede suscitar sospechas referentes a su posible falta de adecuación a las reglas de competencia desleal que regulan el mercado de bienes y servicios.

$\mathrm{Y}$ es que al tener un carácter de mera «colaboración social» el sujeto que los presta únicamente percibirá por el trabajo realizado una suerte de compensación por molestias, muy inferior por tanto al 
hipotético precio de mercado que procedería abonar si se contrataran los citados servicios con carácter profesional (aunque los trasportes compartidos son los trabajos colaborativos que tienen mayor aceptación social ${ }^{5}$, existen múltiples actividades que se pueden prestar a través de estas formas de actividad: transportes, cuidado de niños y ancianos, cocina casera, atención del hogar, paseos de perro, montaje de muebles, o en definitiva, cualquier tipo de actividad que pudiera considerarse incluida en lo que se viene denominado «bancos de tiempo $\left.{ }^{6}\right)$. Se trata de un tipo de colaboración en virtud de la que se presta cualquier tipo de actividad o servicio que habitualmente podría prestarse en un entorno familiar o amistoso, pero que en esta ocasión se realiza por personas que no mantienen entre sí otro vínculo que el del interés ${ }^{7}$.

Es precisamente su falta de regulación el principal factor que ha motivado su proliferación en los últimos años. Y es que al permanecer alejadas de los costes fijos que implicaría cualquier posible tributación o cotización por los servicios prestados, el sujeto que las presta las percibe como actividades «rentables».

${ }^{5}$ GonZález Orden, D., Vallejo Andrada, A., Sarasola, J.L., "Nuevos movimientos sociales: el transporte: El caso Bla-BlaCar y Uber», IJERI: International journal of Educational Research and Innovation, núm. 3, 2015, págs. 143-155; Velasco SAN PEDRO, L.A., "El consumo colaborativo en el transporte de personas», Diario La Ley, núm. 8601, 2015.

${ }^{6}$ A través de los «bancos de tiempo» se intenta obtener un intercambio recíproco de servicios entre dos o más sujetos o, en el caso de que no exista un servicio intercambiable, a cambio de una compensación económica por las molestias generadas, cuyo importe (por su propia naturaleza), ha de ser muy inferior al precio de mercado. Al respecto, se ha afirmado que los bancos de tiempo, correctamente utilizados, constituyen una herramienta muy útil para ayudar a alcanzar la igualdad entre hombres y mujeres, facilitando la conciliación de la vida laboral y familiar. Sobre este tema, véase LEGARRETA IZA, M., "Cuidados y sostenibilidad de la vida: una reflexión a partir de las políticas del tiempo", Papeles del CEIC, International Journal on Collective Identity Research, núm. 1, 2014, págs. 1 y ss. del soporte informático.

${ }^{7}$ Como es sabido, quedan excluidos del ámbito laboral los trabajos familiares (art. 1.3.e ET) y los trabajos restados a título de amistad, benevolencia o buena vecindad (1.3.d ET). Ahora bien ¿cabe admitir la prestación de un servicio no lucrativo entre personas que no mantienen entre sí ningún tipo de relación personal o social? ¿Cómo se podría en esos casos diferenciar una mera actividad de colaboración social de una relación profesional -laboral o civil- no declarada? Contestando a estas preguntas, véase AlONSo OlEA, M., «Trabajos familiares y amistosos, benévolos y de buena vecindad [art. 1.3.d) y e)]», Civitas. Revista española de Derecho del Trabajo, núm. 100, 1, 2000 (Ejemplar dedicado al Estatuto de los Trabajadores veinte años después), págs. 83 y ss; y más recientemente, RodRíGUEz CARDO, I.A., "Los trabajos amistosos, benévolos y de buena vecindad como prestación de servicios no laboral: un repaso a la doctrina judicial reciente», Actualidad laboral, núm. 22, 2007, págs. 2672 y ss. 
En particular, los «trabajados colaborativos», entendidos como modernas manifestaciones de los clásicos trabajos amistosos, en los que las nuevas tecnologías desempeñan un papel fundamental en la conexión prestador/receptor del servicio, pueden gran similitud con dos fenómenos de «trabajo negro»: $1 .^{\circ}$ Por una parte, a la relación laboral no declarada prestada para un empleador no empresario (esto es, que no es titular de una organización productiva destinada a ofertar en el mercado sus productos o servicios -normalmente un cabeza de familia-), $2{ }^{\circ} \mathrm{Y}$ por otra, respecto a los trabajos incipientes realizados por cuenta propia por emprendedores noveles al margen de la Seguridad Social. Por ese motivo, desde el punto de vista práctico, el principal objetivo del intérprete recae en diferenciar las colaboraciones prestadas a título de amistad, benevolencia y buena vecindad, de lo que en realidad podrían considerarse relaciones con causa productiva encubiertas, tanto si se prestan por cuenta ajena o por cuenta propia. Y es que los difusos contornos de los conceptos de «amistad», «beneficencia»y «vecindad» hacen particularmente complejo llevar a cabo este proceso de identificación.

\section{FALSO TRABAJO AUTONOMÍO}

Por último, debe tenerse presenta que una de las formas más importantes de eludir la aplicación de la legislación laboral, consiste en encubrir lo que en realidad es una prestación laboral de servicios de la que se beneficia un empresario, bajo la forma del trabajo prestado por cuenta propia a un cliente. A través de los supuestos de autonomía aparente o simulación ${ }^{8}$ se excluyen sin justificación determinadas figuras contractuales del ámbito protector que les correspondería en virtud de su auténtica naturaleza jurídica9 ${ }^{9}$ Y es que expresando una causa contractual que no se ajusta a la realidad se pretende adaptar el régimen jurídico aplicable a una concreta relación a las preferencias

${ }^{8}$ Al respecto, LuJÁn AlCARAZ, J. explica que «además de las actuales y muy numerosas manifestaciones de la tradicional huida del Derecho del Trabajo propia de la economía sumergida y el empleo clandestino, especialmente intensa en los últimos años a causa de la inmigración ilegal, la principal vía de escape del ordenamiento laboral sigue siendo la que se produce en zonas grises del contrato de trabajo». «El ámbito subjetivo del Estatuto de los trabajadores", Revista del Ministerio de Trabajo y Asuntos Sociales, núm. 58, 2005.

${ }^{9}$ Revilla Esteve, E. denomina a estas manifestaciones de huida ilícita del Derecho del Trabajo «sector terciario retrasado», que abarca al mundo de la economía sumergida. La noción de trabajador en la economía globalizada, Thomson-Aranzadi, Pamplona, 2003, pág. 277. 
de los contratantes (o al menos, del contratante más fuerte) ${ }^{10}$. En la práctica, constituyen uno de los fenómenos más importantes de «huída ilícita del Derecho del Trabajo» que se vienen presentando en el mercado de trabajo, a través de los que se coloca en una importantísima situación de precariedad laboral a los trabajadores afectados.

La jurisprudencia cuenta ya con criterios sólidos como para dar respuesta a las formas más frecuentes de simulación, pero la realidad social, consciente de eso, idea constantemente nuevas fórmulas de simulación ${ }^{11}$, utilizando coberturas jurídicas cada vez más complejas y menos conocidas para encubrir una relación laboral; o bien formas contractuales clásicas pero que hasta el momento no habían tenido demasiada aplicación. De tal manera, el proceso de identificación de estas relaciones laborales encubiertas, puede llegar a ser mucho más complejo de lo que a primera vista pudiera parecer.

Es cierto que durante el siglo XXI se ha producido un acercamiento muy importante entre las modernas formas de realizar trabajos dependientes y las prestaciones autónomas, pues cada vez con más frecuencia trabajadores por cuenta ajena, normalmente debido a su alta cualificación, gozan de un margen de independencia y autodecisión impensable en los modelos de producción fordistas ${ }^{12}$. Tal similitud en ocasiones, se aprovecha intencionadamente para crear una apariencia contraria a la realidad ${ }^{13}$. De tal manera, alternativas con-

${ }^{10}$ Acerca de actual tendencia elusiva del ámbito laboral, véase RoDRíGUEz-PIÑERo y Bravo-Ferrer, "La huida del Derecho del Trabajo», Relaciones Laborales, 1992, tomo II.

${ }^{11}$ Rodríguez-PiÑero, M., declara que «junto a las tendencias elusivas tradicionales -que han buscado una cobertura de legalidad, aunque fraudulenta o simulada-, aparecen nuevos supuestos de actuación en abierta ilegalidad». "Economía sumergida y empleo irregular», Relaciones Laborales, 1985, tomo I, pág. 44.

${ }_{12}$ Es muy clara la argumentación jurídica de ciertas sentencias, a través de la que el juzgador afirma que "la línea divisoria entre el contrato de trabajo y otros de naturaleza análoga, como es el de ejecución de obra, el de arrendamiento de servicios, el de comisión, etc., regulados por la legislación civil o mercantil, no aparece nítida ni en la doctrina científica, ni jurisprudencial, ni en la legislación, ni siquiera en la realidad social», entre otras, las SSTS, (Sala de lo Social) de 27 de mayo de 1992 (RJ 1992/3678), y de 14 de febrero de 1994 (RJ 1994/1035). Como reconoce CASAS BAAMONDE, M.E., «las fronteras que separan la «laboralidad» de la «no laboralidad» no han estado nunca claras ni definitivamente fijadas (...)» en «El derecho del trabajo ante las nuevas formas de trabajo", Derecho de las Relaciones Laborales, núm. 7, 2015, pág. 710 .

${ }^{13}$ LÓPEZ GANDía, J. indica que "asistimos a una diversificación de las formas de prestar trabajo dónde aparecen algunas características que han afectado tanto a la prestación de un trabajo por cuenta ajena como a la simulación o disimulación de relaciones laborales bajo otros contratos civiles o mercantiles», en «Descentralización productiva y cooperativas de trabajo», Revista de Derecho Social, núm. 20, 2000, pág. 39. 
tractuales en principio lícitas, en lugar de servir para organizar el proceso de producción de la manera que el empresario considere más adecuada, en realidad se están utilizando fraudulentamente para conseguir la aplicación del régimen jurídico que mejor se adapte a los intereses empresariales ${ }^{14}$. Y es que, haciendo teóricamente uso de la «libertad de empresa» que reconoce la constitución, el empresario recurre cada vez con más frecuencia a trabajadores independientes para satisfacer las mismas necesidades productivas que antes se llevaban a cabo por trabajadores dependientes, lo que ocurre es que esta opción formal no siempre se adecua a la verdadera naturaleza del vínculo, dando lugar a fenómenos de simulación ${ }^{15}$.

Como es sabido, la simulación es la declaración de un contenido de voluntad no real, emitida conscientemente y de acuerdo entre las partes, para producir con fines de engaño la apariencia de un negocio jurídico que no existe o que es distinto al que realmente se ha llevado a cabo. En el ámbito laboral, la simulación genera un supuesto ilícito pero muy extendido de precariedad laboral de compleja solución, pues para descubrirlo, no basta con probar simplemente que se está realizando una prestación retribuida de servicios, sino que además, ésta se realiza en régimen de dependencia laboral.

En concreto, la «simulación relativa» es la más frecuente en el ámbito laboral ${ }^{16}$. Y es que en la práctica, en gran número de ocasio-

${ }^{14}$ Así, lo que en principio parece no ser más que un ejemplo de «huida lícita del Derecho del Trabajo» materializada a través de la potenciación del trabajo autónomo en la empresa moderna, en realidad está amparando un fenómeno de «huida ilegitima» haciendo pasar desapercibida la naturaleza laboral del vínculo bajo una falsa cobertura formal.

${ }^{15}$ Galiana Moreno, J. M., aprecia que «es sin duda en la elección de la figura contractual adecuada a la relación donde con más frecuencia se producen actuaciones fraudulentas, unas veces para eludir la concertación de un verdadero contrato de trabajo, otras, por el contrario, para aparentar su existencia, y las más de las veces, para impedir que éste, una vez concertado, se configure como un contrato indefinido». "El fraude de ley en las relaciones de trabajo: un análisis jurisprudencial», Cuestiones actuales de Derecho del Trabajo. Libro homenaje al profesor Alonso Olea. MTSS, Madrid, 1990, pág. 451.

${ }^{16}$ Cualquier fraude es reprobable. Tanto los casos en que se encubre una verdadera relación laboral bajo otra forma jurídica con el fin de eludir obligaciones laborales y con la Seguridad Social (simulación relativa), como en los casos (menos frecuentes en la práctica) en que se fije que existe una relación laboral, en realidad totalmente inexistente, con el fin de gozar de la protección del Derecho del Trabajo -situación que en la práctica normalmente se presenta unida a razones de familiaridad o amistad con el que dice ser su empresario- (simulación absoluta). Múltiples decisiones judiciales aplican en el ámbito laboral las consecuencias de la simulación relativa que dispone el art. 1274 CC. Entre otras, la S. A.P. de Tarragona (Sección 3. a) de 24 de noviembre de 2000, (rollo 445/1999). 
nes, se intenta hacer pasar desapercibida una relación laboral, encubriéndola bajo una cobertura jurídica que no le pertenece ${ }^{17}$.

$\mathrm{El}$ art. 38 de la CE implícitamente reconoce al empresario la facultad de organizar del modo que estime más conveniente los recursos disponibles para una satisfacción óptima de sus intereses. Esta libertad de organización incluye también libertad de criterio para decidir la forma contractual que considere más adecuada para lograr la realización puntual de un servicio profesional, pero la libertad de elección no significa que exista una plena libertad de identificación, de manera que la calificación del vínculo jurídico debe adaptarse al contenido de los derechos y obligaciones que dicha relación verdaderamente genera, y no a las preferencias de los contratantes.

En otras palabras, la decisión de obtener la misma prestación de servicios en régimen de independencia o autonomía debe realizarse por acuerdo de voluntades en el momento de iniciar la prestación de servicios, pero el empresario no es libre para ofrecer, atendiendo exclusivamente a su interés personal, una u otra denominación a la relación que ha iniciado. Y como de la naturaleza del vínculo va a depender el régimen jurídico que se aplique en cada caso, la cuestión de la calificación pasa a ser un derecho indisponible por las partes $(6.2 \mathrm{CC}$ y 3.5 del ET $)^{18}$.

La libertad constitucional de empresa (38 CE) tiene siempre el límite del respeto al ordenamiento jurídico en su conjunto. Calificar libremente una prestación de servicios iniciada en el seno de la estructura productiva independientemente de lo que se desprenda de su

${ }^{17}$ Son muy variadas las modalidades de fraude a través de las que se pretende dar lugar a un fenómeno de «huida ilegítima del Derecho del Trabajo» encubriendo bajo una cobertura formal falsa la relación que verdaderamente cumple todos los presupuestos constitutivos del contrato de trabajo. Lo más frecuente es que se utilicen formas contractuales de naturaleza no laboral que en la materialización de sus respectivas obligaciones puedan guardar alguna similitud con la ejecución de una prestación laboral de servicios: el arrendamiento civil de obra o de servicios, ciertas formas asociativas en las que media u socio industrial, las falsas becas e incluso las aparentes colaboraciones voluntarias que verdaderamente encubren una finalidad cambiaria.

${ }^{18} \mathrm{El}$ consentimiento del trabajador dependiente es imprescindible para completar la falsa cobertura jurídica, pero la indisponibilidad de derechos lo transforma en un dato intrascendente. Al mismo tiempo, en la mayoría de ocasiones su condición de parte débil y su necesidad de trabajar para tener acceso al puesto de trabajo, priva al sujeto de fuerza suficiente como para decidir la cobertura formal de la relación que inicia con el empresario, por eso, de todas maneras no representa un papel significativo en el fenómeno simulatorio, sino que se limita a aceptar las condiciones contractuales que la otra parte le impone. 
ejecución real, desvirtuaría la naturaleza jurídica del vínculo que se ha formalizado.

En estas formas de simulación, el fraude de ley se apoya en una alternativa contractual, aparentemente lícita, para conseguir un resultado prohibido por el ordenamiento jurídico. Creando una falsa apariencia jurídica de autonomía, el empresario contratante consigue dos grandes ventajas. Por un lado evita tener que hacer frente a las obligaciones con la Seguridad Social en materia de cotización por sus trabajadores dependientes; Y por otro, elude parte de los costes fijos que la mano de obra supone dentro de los costes totales de los factores de producción y consigue adaptar fácilmente las relaciones contractuales vigentes en cada momento a las necesidades puntuales de la empresa.

A través de distintos tipos de "falsos indicios» se formaliza una relación contractual cuya causa declarada no se corresponde con la causa real que da origen al contrato. Ante esta situación, el primer paso de un proceso de identificación correcto será descartar en la ponderación indiciaria cualquier compromiso que no haya sido objeto de materialización efectiva entre los contratantes ${ }^{19}$.

A la hora de llevar a cabo este proceso de identificación, resulta útil tener en cuenta que, nuestra jurisprudencia más reciente rechaza que exista cierto tipo de colaboración productiva que deba, por naturaleza, calificarse siempre como actividad laboral o como actividad desarrollada por un profesional por cuenta propia. Y es que hoy en día (salvo la excepción prevista para los trasportistas por cuenta propia que configura el Estatuto de los Trabajadores como una presunción iuris et de iure) parece que no existen actividades concretas que necesariamente, deban prestarse por cuenta propia o por cuenta ajena. Hoy en día nada impide concertar un contrato de trabajo con profesionales cualificados dotados de un margen inherente de decisión y responsabilidad (como médicos o abogados de empresa, en el

${ }^{19}$ Sea cual sea el objetivo de la simulación, el fraude se perfecciona a través de técnicas muy variadas destinadas a crear una apariencia formal distinta a la real. El supuesto más frecuente es aquel en el que las partes, al formalizar por escrito una relación contractual utilizan una calificación equivocada; pero la identificación se complica cuando, como consecuencia de la falsa causa contractual que manifiestan los contratantes, se produce el cumplimiento de ciertas obligaciones jurídicas directamente derivadas de dicha calificación incorrecta (alta en el RETA, abono del Impuesto de Sociedades, o -hasta hace unos años- el pago del IAE, etc.). Al considerarse que estas circunstancias derivan de un dato meramente formal (la denominación de los contratantes) los posibles rasgos que puedan desprenderse de ella, también carecerán de valor indiciario, puesto que no siempre se ajustan estrictamente a la verdadera naturaleza contractual del caso controvertido. 
que su cualificación y deontología profesional impiden al empresario emitir órdenes o instrucciones que pretendan incidir sobre las reglas técnicas propias de su especialización) o concertar arrendamientos civiles de servicios con profesionales poco cualificados, ni siquiera aunque el tipo de contrato implique desempeñar una actividad constante para un mismo cliente, incluso en régimen de exclusividad.

Eso sí, no se puede negar que la progresiva flexibilización de la dependencia laboral hace difícil en muchas ocasiones diferenciar la prestación laboral de otras formas de colaboración productiva, pues al atenuar su intensidad se produce un acercamiento de la causa contractual que da origen a relaciones jurídicas de naturaleza opuesta: seguirán siendo causas contractuales totalmente diferentes pero se dificulta su identificación práctica. También la presencia de dependencia técnica o de dependencia económica, muy distintas a la dependencia jurídica que identifica al contrato de trabajo, pueden confundir al intérprete, por lo que son vías que se suelen utilizar para perfeccionar el fraude.

Lo mismo ocurre con la dependencia ideológica que caracteriza ciertas colaboraciones productivas de naturaleza no laboral desempeñadas en el seno de sindicatos o partidos políticos; o incluso la participación altruista de un voluntario social puede estar encubriendo una verdadera relación laboral, disimulando la dependencia jurídica bajo el margen inherente de integración de distinta naturaleza jurídica. Sociedades unipersonales, aparentes trabajos familiares, sociedades civiles irregulares o simples funciones de tutoría, instrucción y coordinación del miembro del equipo de mayor experiencia o antigüedad pueden servir para ocultar una relación laboral. Pero no sólo eso: la actual tendencia a reducir la estructura productiva recurriendo a la técnica de la descentralización o externalización no siempre lleva aparejada la concertación de verdaderos contratos civiles de suministro de bienes o servicios, sino que puede utilizarse para encubrir falsamente la subsistencia de vínculos laborales ${ }^{20}$. Sea cual sea la situación que se plantee, la identificación exigirá un proceso previo de análisis que consistirá en determinar en cada caso si existe o no un trabajo productivo y si además el trabajador actúa en régimen de «dependencia laboral» y no bajo otra forma de vinculación, más o menos intensa pero de otra naturaleza.

Pero no sólo eso. La figura del trabajador autónomo económicamente dependiente (TRADE) reconocida en nuestro ordenamiento

${ }^{20}$ LÓPEZ ANIORTE, M.C., "La descentralización productiva y su incidencia en la relación individual de trabajo», Laborum, Murcia, 2003. 
jurídico por primera vez con la entrada en vigor de la Ley 20/2007 por la que se regula el Estatuto del Trabajo Autónomo, complica todavía más el proceso de identificación, pues acerca aún más la frontera ya por sí difusa entre modalidades contractuales de diferente naturaleza jurídica.

Ahora bien, ¿qué ocurre cuando se ha dado lugar a un fenómeno de simulación? Una vez detectada esta forma de fraude, la causa verdadera que motivó la contratación es la que ha de prevalecer y no la causa aparente que manifiestan las partes, pues la simulación en realidad no es más que una concreta aplicación del fraude de ley ${ }^{21}$. El resultado será entonces la aplicación de la norma que trataba de eludir, en este caso, la plena aplicación de la legislación laboral con todas las consecuencias que ello implica, por ejemplo en lo que a la cobertura por el RGSS se refiere. Pero la solución que el art. 1276 CC ofrece a los casos de simulación puede completarse en el campo laboral con la regla de la «realidad jurídica».

El citado "principio de realidad jurídica» ${ }^{22}$, ayuda a hacer efectiva la solución que ofrece el art. 1276 del Código Civil, pues según este criterio interpretativo, sustentado sobre las reglas de la lógica, la conceptuación de una relación jurídica tiene que llevarse a cabo a raíz de los concretos derechos y obligaciones que verdaderamente se hayan materializado en algún momento durante el desarrollo de la relación

${ }^{21}$ En realidad, el art. $1276 \mathrm{CC}$ al regular las consecuencias de la expresión de causa falsa, repite para la simulación las consecuencias que ya preestableció el art. 6.4 CC.

${ }^{22}$ En el ámbito laboral, el TS asentó históricamente el «principio de realidad jurídica» como forma de evitar la simulación. Una reiterada jurisprudencia ha venido manifestando que la determinación de si una relación inter partes tiene o no naturaleza laboral, «no depende ni de cómo la denominen ni la conciban las partes, ni de ninguna decisión ni resolución administrativa, sino que tan sólo compete a los órganos judiciales que han de atender a su verdadero contenido». En estos términos, entre otras, las SSTS (Sala de lo Social) de 14 de noviembre de 1983 (RJ 1983/5595), de 27 de marzo de 1984 (RJ 1984/1612); de 29 de octubre de 1984 (RJ 1984/5344); de 6 de junio de 1987 (RJ 1987/4132). En la misma línea, la STS (Sala de lo Social) de 13 de junio de 1988 (RJ 1988/5272); y las SSTS (Sala de lo Social) de 13 de abril de 1989 (RJ 1989/2967), de 10 de abril de 1984 (RJ 1984/2065), de 18 de abril de 1988 (RJ 1988/2973), de 21 de julio de 1988 (RJ 1988/6214), y de 5 de junio de 1990 (RJ 1990/5019). Prácticamente en los mismos términos, esta teoría interpretativa, se sigue recogiendo por jurisprudencia más reciente. Sirvan como ejemplo la STSJ del País Vasco de 7 de abril (AS 1998/2095); la STSJ de Navarra (Sala de lo Social) de 14 de febrero de 2001 (AS 2001/849), la STSJ del País Vasco (Sala de lo Social) de 18 de marzo de 2003 (AS 2003/2564), la STSJ de Cataluña, (Sala de lo Social) de 14 de enero de 2003 (AS 2003/446) y muy recientemente, la STSJ de Cataluña (Sala de lo Social) de 21 de abril de 2005 (AS 2005/1581). Todas ellas advierten que la calificación del vínculo «no se desvirtúa por el nomen iuris con el que las partes denominaron sus contratos». 
jurídica y no a partir de meros derechos u obligaciones que, aunque incorporadas formalmente al texto del contrato, nunca tuvieron una manifestación efectiva.

En virtud de este criterio, en los casos en que ciertos derechos u obligaciones recíprocas únicamente consten en el texto del contrato sin tener ningún tipo de ejercicio práctico demostrable, serán totalmente irrelevantes ${ }^{23}$. Sólo así se podrá demostrar que la aparente causa contractual que daría origen a un contrato civil no existe en realidad, pero en cambio, concurren todos los elementos fácticos necesarios para constatar la existencia de una relación laboral (1.1. ET y 1276 CC $)^{24}$.

\section{REFLEXIONES EN TORNO A LA SITUACIÓN ACTUAL Y SUS POSIBLES SOLUCIONES}

En pleno siglo XXI, puede ocurrir incluso que algunas formas de inestabilidad y precariedad aparezcan enlazadas o superpuestas, de modo que la desigualdad entre las partes de $\mathrm{n}$ contrato de trabajo pueda llegar a ser, sí cabe, mayor. Así, es frecuente encontrar contratos temporales no formalizados o modalidades ilícitas de trabajo ne-

${ }^{23}$ Por medio de esta técnica interpretativa se permite deslindar los «datos reales», de aquellos otros «datos teóricos o formales»-que carecen de valor indiciario- y que muchas veces se han introducido únicamente con la finalidad de encubrir una relación laboral bajo una forma jurídica que no le pertenece. Esta opinión aparece expresada reiteradamente en nuestra jurisprudencia. Entre otras, la STSJ de Andalucía, Málaga, (Sala de lo Social) de 16 de enero de 2003 (AS 2003/1518) argumenta que «debe tenerse en cuenta que los actos o negocios jurídicos tienen la naturaleza que se deriva del conjunto de derechos y obligaciones que encierran, es decir de la verdadera realidad, cualquiera que sea la terminología empleada y con independencia de la calificación jurídica que le asignen las partes, por lo que la determinación de la naturaleza laboral contencioso-administrativa, mercantil o civil de la relación presenta materia que escapa a la libre disposición de los litigantes, ya que se trata de una labor que ha de verificarse sobre el contenido real de las prestaciones concertadas y de la concurrencia de los requisitos y presupuestos que legalmente definan y delimiten una singular figura contractual, por lo que debe prevalecer siempre el auténtico carácter jurídico, en lo personal y en lo funcional, exteriorizado en los actos desarrollados por los interesados en su efectiva ejecución».

${ }^{24}$ Por ese motivo, sólo podrán calificarse como «indicios» a favor o en contra de la laboralidad, aquellos datos que hayan tenido alguna clase de aplicación práctica, por pequeña que sea, y sobre ellos se valora la concurrencia de los cinco elementos constitutivos del contrato de trabajo. Muy clara es la reflexión que incorpora la STSJ de Cataluña, (Sala de lo Social) de 21 de abril de 2005 (AS 2005/1581) que determina que «la calificación de la relación como laboral no queda a la libre disposición de las partes, sino que debe surgir del contenido real de las prestaciones concertadas y de la concurrencia de los requisitos que legalmente delimitan el tipo contractual». 
gro, lo que hace su identificación todavía más confusa. Sin olvidar los casos en los que una prestación de servicios no formalizada presenta un contorno ambiguo que dificulta su identificación como relación, civil, mercantil o laboral y ocasiona dudas sobre el régimen jurídico aplicable.

Las diversas formas de fraude de las que adolece el mercado de trabajo nacional y que se han puesto de manifiesto en este trabajo, presentan como elemento común el hecho de perseguir reducir los costes vinculados al trabajo dependiente. Y es que eludiendo las obligaciones en materia de cotización a la Seguridad Social se consigue, ilícitamente, reducir los costes fijos vinculados a la producción de bienes y servicios. Tan frecuentes resultan ser estos comportamientos (manifestados en cualquiera de las modalidades expuestas) que parecen haberse convertido en una práctica socialmente «tolerada».

Pero los problemas que desencadenan este tipo de situaciones no solo están relacionados con el fraude la Seguridad Social y la desprotección del trabajador afectado, sino que presentan una trascendencia mucho mayor: pueden comprometer seriamente el futuro de la Seguridad Social, ya por sí mismo incierto ante un número cada vez más reducido de cotizantes. Tan enquistado ha quedado ya este problema dentro del mercado de trabajo español que posiblemente para poder solucionarlo se necesitará adoptar reformas estructurales. Es decir, quizá se debería acometer un cambio radical en determinadas instituciones laborales consideradas esenciales en el régimen jurídico-laboral de forma que quizá, en un futuro cercano, podrían quedar configuradas de forma muy diferente a como las conocemos hasta ahora.

Ya ha quedado claramente demostrado que las diferentes técnicas ideadas hasta ahora con el fin de premiar y potenciar la contratación indefinida no han surtido los efectos deseados. Por mucho que cada año su contenido y metodología se actualice con el fin de hacerlas más atractivas para nuestras empresas, las cifras de contratación laboral (al margen de las vinculadas al empleo público) se ocupan cada año de demostrar su constante fracaso. Y es que ninguna de las estrategias ideadas hasta ahora ha conseguido hacer olvidar las ventajas que el empresario actual encuentra en la contratación temporal.

$\mathrm{Al}$ respecto, no estaría de más emprender campañas de concienciación social que tuvieran como objetivo principal informar a los potenciales incumplidores de las normas fiscales y laborales de las importantísimas sanciones económicas que este tipo de conductas llevan aparejadas. Y es que aunque todo el mundo conoce la existencia de los cuerpos de Inspectores de Trabajo y de Inspectores de Ha- 
cienda y el importante papel que desempeñan en la tutela del cumplimiento de las normas, pocos conocen con exactitud el elevadísimo importe económico que representaría la imposición de una sanción por este tipo de comportamientos, por lo que su efecto disuasorio, se atenúa.

Posiblemente sea llegados a este punto cuando proceda valorar si resultaría conveniente replantear las modalidades de contratación laboral existentes hasta ahora, simplificándolas al máximo, quizá incluso, por qué no, dejando paso a un contrato de trabajo único. Y es que éste (como muy recientemente ha traído a colación la STJUE de 14 de septiembre de 2016, en el caso Diego Porras) a pesar de la demonización de la que viene siendo objeto, bien planteado, posiblemente reportaría más ventajas que inconvenientes, pues haría desaparecer no sólo las causas de la extinción del contrato de trabajo, sino también la temporalidad de la contratación laboral ${ }^{25}$. En otras palabras, a la vista de la situación actual y de los infructuosos planes de actuación sucesivamente iniciados ¿realmente existe otra forma eficaz de evitar el abuso en la contratación temporal que suprimirla?

Pero no sólo eso. Una vez reconocido el incierto futuro de la Seguridad Social, ha llegado también el momento de admitir que la configuración del actual sistema, basado en criterios de reparto, no disuade del fraude, como la propia realidad práctica se ocupa de confirmar, lo que hace peligrar la subsistencia del modelo. Y es que parece que ya ha quedado claramente demostrado que la conciencia social de la solidaridad quiebra en el momento en el que el sujeto empieza a con-

${ }^{25}$ En la práctica, en los casos de extinción del contrato de trabajo, el trabajador afectado, por lo general, viene percibiendo una indemnización que oscila entre los 12 días (prevista, como máximo para los supuestos de extinción de un contrato de trabajo temporal) y los 20 días (pues es ésta la que corresponde ante cualquier supuesto de extinción por las cada vez más amplias y flexible causas objetivas o por la extinción contractual derivada de una modificación sustancial de las condiciones de trabajo). A la vista de esta situación, resulta obligado planear la siguiente cuestión: en el caso de implantar la figura del contrato de trabajo único ¿cuál debería ser la indemnización única, que con carácter general correspondiera a todo trabajador, independientemente de cuál haya sido la causa en virtud de la cual se haya extinguido su relación laboral, para que este contrato de trabajo único, lejos de ahondar en la precariedad laboral, consiga atemperarla? ¿Los interlocutores sociales admitirían una indemnización única cuantificada en la media de los diferentes tipos de indemnizaciones preexistentes? En otras palabras, ¿la solución a este complejo problema de acuerdo de voluntades nos la podría dar una simple fórmula matemática? Pues si $12+20+45 / 3=25,6$ ¿no podrían ser los 25 días de trabajo por año trabajado una buena medida que, sin incrementar de forma excesiva los costes empresariales, consiguiese fácilmente la aceptación por parte de los representantes de los trabajadores? Eso sí, debe incidirse en que el contrato de trabajo único, de llegar a implantarse, no haría desaparecer en modo alguno las causas y las consecuencias de la nulidad del despido. 
siderar que su propia aportación le representa un coste excesivo del que no va a obtener un beneficio personal y directo.

Obviamente, se trata éste de un problema de difícil solución, sobre el que, con mayor o menor éxito, se ocupan insistentemente de luchar los diferentes instrumentos de control previstos en nuestro ordenamiento jurídico. Pero a la vista de la situación actual del mercado de trabajo, quizá haya llegado el momento de valorar si sería conveniente reestructurar la naturaleza del sistema, pasando a ensayar las posibles ventajas que un sistema de capitalización podría presentar sobre el sistema tradicional de reparto. A estos efectos, no se puede negar que un sistema de capitalización produciría un efecto totalmente contrario al que se detecta en el modelo vigente: cada partícipe del sistema tendría un enorme interés acumular cotizaciones y prolongar en la medida de lo posible su vida activa, sabiendo que con ello mejorará la dotación de su fondo personal, llegando incluso a hacer intolerable cualquier propuesta de fraude.

Pero existe otra cuestión sobre la que también se debe incidir: para que sean bien aceptados por empresas y trabajadores, estos cambios tan importantes que desde estas líneas se proponen, deberían ir acompañados de una generalizada reducción fiscal y también, de una notable minoración de las cuotas de cotización tanto al RGSS como al RETA. Y es que si las estrategias apuntadas finalmente consiguen el efecto deseado de eliminar la dualidad y la economía sumergida del mercado de trabajo, no se puede negar que la recaudación extraordinaria que implicaría la regularización de las actividades que hasta ahora se desarrollaban de forma no declarada, permitirá reducir la carga impositiva sobre los cotizantes y contribuyentes.

En resumen: para luchar contra un conjunto de problemas tan asentados en nuestro mercado laboral, se hace imprescindible utilizar un conjunto variado de estrategias de actuación, de importantísima trascendencia práctica. Y es que sólo actuando de forma simultánea sobre diversos frentes y aplicando de forma combinada medidas novedosas, se conseguirá refundar las reglas de funcionamiento del mercado laboral, basadas ya en un esquema renovado en el que no tenga cabida la ilegalidad.

\section{BIBLIOGRAFÍA}

AAVV, Memoria sobre la situación socioeconómica y laboral de España (2016), Consejo Económico y Social, Madrid, 2016. 
Alonso Olea, M., «Trabajos familiares y amistosos, benévolos y de buena vecindad [art. 1.3.d) y e)]», Civitas. Revista española de derecho del trabajo, núm. 100, 1, 2000 (Ejemplar dedicado al Estatuto de los Trabajadores veinte años después), págs. 83 y ss.

CASAs BaAmonde, M.E., "El Derecho del trabajo ante las nuevas formas de trabajo», Derecho de las Relaciones Laborales, núm. 7, 2015, págs. 709 y ss.

Galiana Moreno, J. M. «El fraude de ley en las relaciones de trabajo: un análisis jurisprudencial», Cuestiones actuales de Derecho del Trabajo. Libro homenaje al profesor Alonso Olea. MTSS, Madrid, 1990, pág.451.

- «Algunos tópicos e incongruencias de las reformas del "mercado de trabajo"», Nueva revista española de derecho del trabajo, núm. 161, 2014, págs. 41-58.

González Orden, D., Vallejo Andrada, A., Sarasola, J.L., «Nuevos movimientos sociales: el transporte: El caso Bla-BlaCar y Uber», IJERI: International journal of Educational Research and Innovation, núm. 3, 2015, págs. 143-155.

LEgARRETA Iza, M., "Cuidados y sostenibilidad de la vida: una reflexión a partir de las políticas del tiempo", Papeles del CEIC, International Journal on Collective Identity Research, núm. 1, 2014, págs. 1 y ss. del soporte informático.

LóPEZ ANIORTE, M.C., La descentralización productiva y su incidencia en la relación individual de trabajo, Laborum, Murcia, 2003.

LÓPEz GANDÍA, J., «Descentralización productiva y cooperativas de trabajo», Revista de Derecho Social, núm. 20, 2000, pág. 39.

LujÁn AlCARAZ, J., «El ámbito subjetivo del Estatuto de los trabajadores», Revista del Ministerio de Trabajo y Asuntos Sociales, núm. 58, 2005.

Revilla Esteve, E., La noción de trabajador en la economía globaliza$d a$, Thomson-Aranzadi, Pamplona, 2003, pág. 277.

RODRíGUEZ CARDO, I.A., «Los trabajos amistosos, benévolos y de buena vecindad como prestación de servicios no laboral: un repaso a la doctrina judicial reciente», Actualidad laboral, núm. 22, 2007, págs. 2672 y ss.

Rodríguez-PiÑERo y Bravo-Ferrer, M., «La huida del Derecho del Trabajo», Relaciones Laborales, 1992, tomo II. 
- «Economía sumergida y empleo irregular», Relaciones Laborales, 1985, tomo I, pág. 44 y ss.

SEMPERE NAVARRo, A.V., "Contratación laboral y libertad de empresa», Revista del Instituto de Estudios Económicos, núm. 4, 2004, pág. 47-108.

SuPIOT, A., Trabajo y empleo: transformaciones del trabajo y futuro del Derecho del Trabajo en Europa, Tirant lo Blanch, Valencia, 1999.

Velasco San Pedro, L.A., "El consumo colaborativo en el transporte de personas», Diario La Ley, núm. 8601, 2015. 